\title{
A Qualitative Study of Leader Behaviors Perceived to Enable Salesperson Performance
}

This study builds on and extends previous sales leadership research by exploring sales professionals' perceptions of effective leadership behaviors. Semi-structured interviews with both sales leaders and salespeople working in a global enterprise software company were examined through a qualitative analysis. Results indicated that participants believed sales leadership played an important role in influencing sales performance. When asked to describe specific sales leader behaviors that best enable salesperson performance, sales professionals - both sales leaders and salespeople - overwhelmingly referenced coaching, followed by collaborating, championing, and customer engaging. We define and describe these four key sales leader behaviors and identify four potential mediating variables (trust, confidence, optimism, and resilience) from which emerges a conceptual framework of sales leader behaviors perceived to enable salesperson performance. We examine these four key sales leader behaviors and mediators in the broader context of leadership theory, particularly transformational, servant, authentic, and adaptive leadership theories. The key contribution of this study is the identification of a set of leader behaviors that are likely to be especially effective in modern sales organizations given that they originated from the perceptions of sales professionals themselves.

Keywords: sales leadership, qualitative research, sales management, sales performance, leadership 
Sales leadership has been recognized as a crucial factor in global sales success (Deeter-Schmelz, Goebel, and Kennedy 2008; Dixon and Tanner 2012; Ingram, LaForge, and Leigh 2002; Ingram et al. 2005; Schwepker and Good 2010). Salespeople need guidance from their supervisors, the sales leaders, as they deal with unprecedented change in the sales environment; especially with respect to increased customer expectations, enhanced competitive activity, and new technologies (Dixon and Tanner 2012; Jones et al. 2005; Schwepker and Good 2010).

Academic sales researchers point out that these trends place "a different set of demands on today's sales force" (Evans et al. 2012, 89), and call for a new kind of leadership as old methods of command and control are being questioned (Dixon and Tanner 2012). Practitioners appear to share this viewpoint. For example, there is a strong and growing interest among sales organizations to engage in sales enablement activities (Dickie 2017), which involve a broad set of sales leader practices focused on providing new information, content, and tools to help salespeople sell more effectively (Albro 2018).

This brings us to the purpose of our study, which is to develop a conceptual model of effective leadership in modern sales organizations. Specifically, we seek to identify the key leader behaviors that sales professionals perceive as enabling sales performance. We identify these behaviors through a qualitative study using in-depth interviews with both sales leaders and salespeople from 12 countries across Asia, Europe, and The Commonwealth analyzed through the lens of leadership theory. Our results reveal that sales professionals perceive four leader behaviors to be particularly effective at enabling sales performance: coaching, collaborating, championing, and customer engaging. Further, we found indications that these leader behaviors may have their influence on performance through trust, confidence, optimism, and resilience. 
The remainder of this article is structured as follows. First, we conduct a literature review of key leadership theories, with an emphasis on models relevant to the sales context. Next, we provide an overview of our research approach, including a description of our sample, methodology, and findings. We then discuss each of the identified leader behaviors and how they might enable sales performance through potential mediating variables. This provides insight into the kind of leadership that is essential for modern sales organizations. We conclude with managerial implications, limitations, and future directions.

\section{Review of Leadership Research in Sales Management Literature}

Leadership has been widely studied across the sales management literature, taking general theories of leadership and applying them to the sales context. In this section we review some key historic and recent developments in sales leadership research and identify two gaps. The first is that sales leadership has not previously been considered from the perspective of the sales professionals themselves, so there has been no consideration of whether sales leadership is, in fact, different from other forms of leadership. Second, the connection between sales leadership and sales performance has not always been explicit in previous research and, where it has, the results have been somewhat contradictory.

Before the 1990s, the most commonly studied leader behavior in sales management research was supervisory feedback (MacKenzie, Podsakoff, and Rich 2001), which originated in the behavioral approach to leadership (Northouse 2016). Supervisory feedback involves contingent reward behavior (e.g., praise for good performance) and/or contingent punishment behavior (e.g., reprimands for poor performance) and is projected to result in subordinates meeting the expectations of their sales manager. Though common in earlier "command and control" 
environments, supervisory feedback is essentially a transactional approach. Because transactional leader behaviors were disappointing in terms of their impact on key outcome variables, a number of leadership researchers shifted their interest toward exceptional or transformational behaviors (Bass 1985; Podsakoff et al. 1990).

Although its origins were earlier (c.f. House 1977), transformational leadership theory came to the fore in the early years of this century, focusing on leadership vision and inspiration as a mechanism for motivating exceptional performance among followers. Transformational leadership theory views feedback as a transactional leader behavior and elaborates on the differences between the transformational and transactional leadership styles (Bass 1985; House 1977). Transformational leader behaviors, on the other hand, are what exceptional leaders do; the theory predicts that they lead to performance that is beyond expectations. Transformational leaders, who are often said to be charismatic, engage in inspirational leader behaviors, including articulating a vision, providing a role model, fostering the acceptance of group goals, providing individualized support, high performance expectations, and intellectual stimulation (Bass 1985; House 1977; Podsakoff et al. 1990).

More recently, the servant leadership framework has been the most extensively-studied leadership theory in the sales management literature. Even though this theory originated over 40 years ago (Greenleaf 1970, 1972, 1977), researchers have been testing and confirming its basic assumptions for the first time through a number of empirical studies over the past decade (see Northouse 2016 for a review). The servant leadership style provides a nurturing environment for followers by attending to their individual concerns. Leader behaviors at the core of the servant leadership process include putting followers first, helping followers grow and succeed, behaving 
ethically, empowering, emotional healing, conceptualizing and creating value for the community (Liden et al. 2014), although the link to performance outcomes is less explicit. Scholars have noted that there is overlap between the leader behaviors of servant leadership and transformational leadership (Grisaffe, VanMeter, and Chonko 2016).

These trends in how leadership theory has been applied to sales management are reflected in Table 1, which provides a full listing of leadership studies in JPSSM since 1990. For each article, we identified the primary leadership theory that was referenced and applied. Table 1 shows that transformational leadership has been most common, with servant leadership a close second. In general, both streams of research have identified a number of leader behaviors said to help sales managers positively impact a variety of salesperson outcomes, including job satisfaction, trust, citizenship behavior, and performance. Consequently, we draw from these two theories as we analyze the qualitative data from the in-depth interviews.

\section{INSERT TABLE 1 ABOUT HERE}

In addition, we draw from two newer theories that are very much in the early stages of development: authentic leadership and adaptive leadership (Northouse 2016). These theories are not found in Table 1. In fact, we could find no sales research that has yet referenced and applied these theories as a primary framework. However, we believe they have the potential to be applicable to the discipline. As suggested by its name, authentic leadership posits that the best leaders are genuine, true to themselves and "real" (Avolio and Gardner 2005). The framework has emerged in reaction to recent corporate scandals that relate to sales. Given the prevalence of these scandals, people are longing for trustworthy leaders who are honest and good, and this is why authentic leaders are argued to be so influential (Northouse 2016). Specific leader behaviors 
associated with authentic leadership include admitting mistakes, acknowledging weaknesses, openly sharing feelings, and being guided by a highly ethical, moral framework.

Adaptive leadership is another relatively new focus area in academic research. Above all, adaptive leaders are focused on helping followers adapt to new situations. These leaders challenge their followers to face and solve difficult problems and provide them with the space and opportunity they need to learn new ways of dealing with the changing environment (Northouse 2016). One specific adaptive leader behavior is protecting the voices from below, which involves giving equal voice and more control to followers; another is maintaining disciplined attention, which is about helping followers address change, rather than avoid it (Heifetz 1994). Given the unprecedented change occurring in the modern sales environment, authentic and adaptive leadership theories appears well-suited to provide insight into how sales leaders can enable salesperson performance.

The preceding literature review shows how theories of transformational leadership, servant leadership, authentic leadership, and adaptive leadership may have relevance to a sales context. Our approach differs from previous leadership and sales leadership research, in that it involves a qualitative analysis of interviews with salespeople and sales leaders by examining their statements through the lens of leadership theory. The advantage of this approach is that the identification of the leader behaviors has originated from sales professionals in a sales context, from the perspectives of both salespeople and sales leaders. The resulting conceptual framework serves as a significant theoretical contribution that is an important first step in identifying leader behaviors that most effectively enable sales performance in today's global sales organizations. 


\section{$2 \quad$ Methodology}

Ladkin (2010) suggests that leadership is a collective process that includes - and in fact, can pass between - both leaders and followers. Consistent with this perspective, we conducted in-depth interviews with both sales leaders and salespeople. The goal was to identify specific leader behaviors that were mentioned by either group as being important in enabling sales performance. Our approach allows a comparison of differing perspectives of sales leaders and salespeople, seeking to identify mechanisms through which the influence on sales performance occurs. Examining both groups enabled us to better understand the dynamics of this leader-follower relationship, and supports calls for research by Schwepker and Good (2010) to explore the sales management/salesperson interactions. The central research question explored is: "What leader behaviors are perceived to enable salesperson performance?"

A social constructionist approach was used to explore perceptions of how leader behaviors enable salesperson performance. Social constructionism "focuses on the ways that people make sense of the world especially through sharing their experiences with others via the medium of language" (Easterby-Smith, Thorpe, and Jackson 2008, 58). Our interpretivist epistemological position "emphasizes the importance of understanding people's perspectives in the context of the conditions and circumstances of their lives" (Ritchie et al. 2014, 22). Consequently, we focused our analysis on how sales professionals construe and experience leadership in their work environment. As explained in the next section, these sales professionals worked in the complex, highly relational business-to-business software industry. 


\section{Sample}

The sample consisted of 36 sales professionals employed at the same global information technology company (henceforth, "IT company"). We used a purposive sample (Guarte and Barrios 2006) consisting of both sales leaders $(n=12,33 \%)$ and salespeople $(n=24,67 \%)$. The majority of these sales leaders (9 out of 12) were delegates of a Master's program at a global business school, and all had experience directly managing salespeople. The sales leaders were asked to invite members of their sales team to participate in the research. To address the problem of selection bias and ensure a broad perspective on effective sales leadership, the sales leaders were asked to stack rank their salespeople from high to low performers, and then to select one high performer, one average performer, and one low performer. Eight of the 12 sales leaders recruited subordinates, which resulted in 24 salespeople added to the sample. The research team was not informed of the performance ranking of salespeople until after the interviews were completed.

Big-ticket technical sales teams tend to be male-dominated and highly-educated and this was the case in our sample, where 95 percent were male and 100 percent had a Bachelor or Master degree. All respondents were over 30 years old; more than half were between the ages of 40-50, reflecting the seniority of this type of sales role. Most respondents were based in Europe (50 percent), with 31 percent based in the Commonwealth (UK, Canada and Australia), 14 percent in Asia, and 6 percent in the Middle East. Respondents had significant work experience, with none having fewer than 5 years and 39 percent having over 21 years. 


\section{Qualitative Data Collection}

Our systematic literature review revealed that 91 percent of the sales leadership research we surveyed came from a positivist perspective and used a quantitative approach and survey techniques to test theoretical hypotheses. From our perspective, however, we saw an opportunity to gain unique insight into this issue by exploring the connection between sales leader behaviors and sales performance through a qualitative study (Miles and Huberman 1994; Blaikie 2007; Lincoln and Guba 2000).

This qualitative research is exploratory and inductive in its design and aims to gain a deeper understanding of leader behaviors, their impact on sales performance, and, most importantly, how these behaviors are perceived. Although existing leadership theory provides a theoretical context for our analysis, the development of ideas and constructs flow from our research data with the goal to uncover specific leader behaviors that are considered to affect salesperson performance in a sales context.

Semi-structured interviews were selected as the method for data collection as they provide a flexible but structured method of obtaining a rich set of data for analysis (Easterby-Smith, Thorpe, and Jackson 2008). Further, this method enables respondents to share experiences and feelings leading to a deeper understanding of the phenomena of interest (Deeter-Schmelz, Goebel, and Kennedy 2008; Fontana and Frey 1994).

Each semi-structured interview lasted between 50 to 110 minutes; in total, we recorded over 47 hours of interviews. The interviews were recorded after informed consent and permission was provided by the participants. The interviews were conducted in English (the working language of 
the company) by a single interviewer. This standard qualitative protocol eliminates interinterviewer differences, enabling similarities and differences between the interviews to be evaluated more accurately.

The interview protocol began with the key research question: "What sales leader behaviors are perceived to enable salesperson performance?" This was followed by a series of open-ended questions assessing respondents' understanding of salesperson performance, enablement, and leadership. As shown in the Interview Protocol (provided in the supplementary online material), the questions covered broad themes in order to understand individual interpretations around the research topic and to help explain social reality. We explored leader behaviors perceived to lead to either exceptional or poor performance. Question probes were used to encourage the respondent to discuss why their identified leader behaviors were effective at enabling (or hindering) salesperson performance. Throughout the interviews, summary checks with the interviewee were completed to ensure that the interviewer was not just interpreting and that they received the message correctly. In some cases there were follow up interviews to explore and clarify points. The interviews gathered subjective accounts and examples of lived experiences in order to help identify evidence of leader behaviors that influence salesperson performance.

INSERT LINK TO WEB INDICES A\&B: INTERVIEW PROTOCOL AND CODING MAPS

\section{Measures and Method of Analysis}

The semi-structured interviews were recorded and transcribed verbatim, and demographic information was captured. Analysis was conducted using the NVivo software tool to organize data and assist with data analysis and interpretation (Bazeley and Richards 2000). Statements of 
the transcripts were systematically coded into categories of leader behaviors. Coding is a key stage of qualitative data analysis where the researcher sorts and organizes data into categories, making it meaningful from frameworks or groups of ideas (Lofland et al. 2006). It represents the process of asking questions about the data and interpreting the data. This process allowed for thematic analysis and eventual development of a coding template (Miles and Huberman 1994). We used a grounded approach (Charmaz 2006) and followed procedures employed by other qualitative researchers (Easterby-Smith, Thorpe, and Jackson 2008; Strauss and Corbin 1998). The official coding process began with the identification of broad based codes (described by Miles and Huberman as a "start list"). This consisted of respondent-driven open coding of the semi-structured interviews into initial non-hierarchical codes. During this process we identified 133 open codes for sales leaders and 135 open codes for salespersons. A short list of examples of these types of codes include: coaching the loss, coaching to build trust, enable focus, encourage new ideas, internal problem solving, resilience, role model, confidence, enable social selling, and encourage cooperation.

During a second stage of coding, (Miles and Huberman's "data display" stage), these broad based codes in the start list were categorized by reordering themes identified. Related themes and sub-themes were grouped and organized to further analyze the data. This was completed by using outputs from NVivo software and various brainstorming analysis sessions. This process helped generate categories of various themes. Examples of these categories include: exceptional sales performance, leader behaviors that enable salesperson performance, leader behaviors that hinder salesperson performance, mediators, modern complex sales environment, and IT company 
ideas for improvement. All of these were considered new, higher level codes emerging from the data.

The third stage of coding (Mile and Huberman's "data reduction" stage) enabled the development of the final categories of leader behavior and mediators that form the core of the study. Next analytical memos (Miles and Huberman, 1994) were written to help draw conclusions about the relationship between the transcribed statements, leadership behaviors, and sales performance. The analytical memos were then cross checked with the respondents' statements and presented as the findings (Miles and Huberman's "validation" and "synthesis" stages).

To illustrate the process from the initial stage, the statement "the sales manager should be able to facilitate and come up with different plans of attack for the deal that may not have been considered by the salesperson" (Salesperson, Europe) was transcribed, read, highlighted as relevant to the research question, and initially coded as coaching on the customer deal. Then in the data display coding cycle this statement was assigned to the broad category of sales leadership behaviors that enable sales performance. It was then grouped with other similar statements to form evidence for the code the art of coaching, coaching the sales process, and the ultimate theme which became the coaching leader behavior, through inductive reasoning. This code was then used in turn to identify other instances of coaching in the data, relating to the original research question regarding sales behavior. After this process was complete for both the sales leaders and salespersons then the final cycle of analysis was conducted (Miles and Huberman's "data reduction"). This process, while time-consuming, enabled trends in the data to 
emerge that were not predicted by existing theory, yet are relevant to understanding perceptions of leadership behaviors that enable salesperson performance in the modern sales context.

To reduce inter-coder differences one member of the team carried out all the coding. An independent leading academic in leadership blind-coded two sales leader transcripts in a test for interrater reliability (IRR). The IRR qualitative research protocol checks whether a small sample of data coded at the descriptive stage would be seen in a similar or different way by another academic in the domain under scrutiny; results were compared with the original coding, and differences discussed. Cohen's Kappa Coefficient was used to measure the degree of agreement between coders. This coefficient ranges between 0 and 1, with a positive kappa indicating that observers agree more than they would by chance. A score of 0.6 is considered substantial agreement and 0.8 or above high level of agreement. The Kappa for this research was recorded at 0.75 , meeting substantial interrater agreement reliability standards and demonstrating robustness in the coding process.

Coding maps are provided in the supplementary online material.

\section{Results and Discussion}

\section{"I think they [sales leaders] hold the real key to their team or salesperson being successful.” (Sales Leader/Europe)}

When analyzing the data, a clear theme emerged that sales leadership is perceived to substantially influence sales performance. This was consistently identified across all participants with both sales leaders and salespeople holding strong views that leadership does enable performance. Respondents shared many ideas on how sales leaders can use leader behaviors to both enable (and hinder) sales performance. In the interview process, the respondents became 
quite animated and emotional when discussing the role of sales leaders in helping or hindering sales performance as seen in the following quotations.

"Showing how to get things done, and who to speak to; a manager with a wealth of knowledge or experience can really benefit a sales executive and help them meet their targets." (Sales Leader/Europe)

"So that kind of noise, the administrative noise, ... too many questions, too many brainstorming sessions, too much documentation around account planning, hinders sales performance ... we will be on four calls about the same flipping deal in a week!' (Sales Leader/The Commonwealth)

The leader behaviors perceived to be the most effective in enabling sales performance, based on frequency of mention, were coaching, collaborating, championing, and customer engaging.

Whilst other leader behaviors were mentioned, these four behaviors emerged overwhelmingly as the key leader behaviors thought to influence sales performance and will therefore be our focus in this paper.

\section{INSERT TABLE 2 ABOUT HERE (Definition Table)}

\section{Coaching Behavior}

"As a leader, you can manage actions; you can't manage results... It comes back to coaching... the actions that are necessary and then putting the discipline around making sure that they [the coaching actions] are actually done." (Sales Leader/Asia Pacific)

Coaching by a sales leader is defined as providing individualized, hands-on assistance and instruction to help salespeople recognize opportunities to improve their job performance. Coaching was extensively mentioned (33\% of statements) by both sales leaders and salespeople in this study as enabling sales performance. This is not surprising given that coaching has received significant attention from both academic sales researchers and practitioners (e.g., Bass 1985; Boehnke et al. 2003; Howell and Avolio 1993; Rich 1998; Shannahan, Bush, and Shannahan 2013). However, there is not uniform agreement on its definition. Some view 
coaching as being equivalent to individualized consideration, which is a dimension of Bass' (1985) transformational leadership. Rich (1998) argued that coaching consists of three constructs: the transformational leader behavior of role modeling, the transactional leader behavior of supervisory feedback, and the mediator of trust.

We found elements in the interviews that related to all these definitions, and elements that expanded our understanding of this construct in the sales context. Our qualitative dataset revealed a richness of information regarding the coaching behavior that might be difficult to extract via typical descriptive survey techniques. Two sub-themes were identified in the coaching leader behavior theme. The first sub-theme was coaching focused on individual development in order to provide opportunities for growth and learning. Sales leaders spoke about the importance of understanding each salesperson and working with that person individually. The respondents spoke about the importance of interactive coaching sessions consisting of advice and feedback that could be used for personal development. Salespeople prefer a sales leader who asks coaching questions and helps them engage in a discussion about situations, rather than a leader who used coaching sessions effectively to tell them what to do. Both sales leaders and salespeople pointed out how this type of coaching enhances self-discovery:

"I have this notion that I actually have got the answer myself, I just need the right questions to answer... they coach by asking questions." (Salesperson/Europe)

"I believe they [sales leaders] should use a coaching attitude - a coaching attitude is the ability to ask questions and help the person find their own way and apply their own change theories which is more powerful than only telling or mentoring the sales guys." (Sales Leader/Europe)

Overall respondents indicated that in order to be effective coaches, sales leaders should be attentive and listen to their salespeople. Sales leaders should not only provide the necessary information to improve their performance, but also provide support and encouragement. 
Secondly, the sub-theme of coaching the sales process was identified. Based on this research, coaching the sales process seems to have two aspects, involving both (1) the art of sales, including the strategic coaching of customer opportunities, and (2) the science of sales, using leading and lagging metrics as a vehicle for coaching. The art of sales - or strategic coaching was described as coaching salespeople on customer opportunities regarding sales strategies, dealmaking and the human element of sales, i.e., working together to strategize on deals, deal reviews, and customer engagements. There were discussions about using coaching behavior to help salespeople move outside their comfort zones with existing customers to expand their territory reach and call into new executives and new clients. The science of sales, on the other hand, was about defining and measuring sales activities using leading and lagging metrics. Historically, the company focused more on lagging indicators (essentially, sales results), but a few select leaders focused on leading indicators (in addition to the lagging indicators) in order to enable sales performance:

"I personally put a lot of effort into measuring the leading indicators because leading indicators will give me a much better bench mark to help me coach people... The problem if you only measure the lagging indicators... the revenue, if anything goes wrong you technically only signal towards the end of the quarter, and it's technically too late to do something about it. Whereas, if you measure both leading and lagging indicators, you can take corrective action with the salesperson as related to performance much earlier in the quarter, and be of much more benefit to the salesperson and subsequently help them improve the performance." (Sales Leader/Commonwealth)

Leading indicators are measurements around sales activities and behaviors, such as sales calls, the number of executives in the sales calls, the number of software demonstrations, and the number of coaching conversations. In this type of coaching, sales leaders ask their salespeople to tell their story using these measures:

"So what happens is that they, in a sense, they coach themselves, all you're doing is facilitating the conversation... and people don't want to come and face you again with a 
lower activity rate, a low pipeline build... and what you find is that the coaching, if you do it properly, that starts to push and move people forward." (Sales Leader/Commonwealth)

Based on our research, the use of leading indicators to facilitate coaching is perceived to enable sales performance.

Finally, our data indicated that effective coaching is tied to trust. That is, when done correctly, trust is built through coaching. One of the sales leaders pointed out that trust is not a behavior, but the result of the coaching leader behavior. Future research might explore whether this process of trust-building contributes to the development (perception) of "authentic leadership".

Another interesting facet of the leader behavior of coaching is how too much of it can be perceived as micromanagement, which may actually hinder sales performance. Sales leaders talked about the thin line between coaching and micromanagement. The data revealed that coaching with leading and lagging indicators is perceived to enhance sales performance through trust. However, it can also work the other way; for example, if the sales leader assertively insists on leading indicators (such as the minimal number of sales calls per day) as they engage in management by exception and correcting behavior, then this would be considered micromanagement and may produce a negative reaction. An example of this is the requirement of salespeople to submit customer meeting reports to management. One sales leader was known to use this information as a tool to help coach and improve performance; however, with other leaders, this practice of customer meeting reporting was seen as micromanagement.

The sales leaders in our sample expressed frustration that they did not have enough time to devote to coaching. One sales leader interviewed was appalled when he discovered the absence 
of coaching within the sales organization. Another leader spoke with frustration about the tendency to forget about coaching when sales is underperforming toward the end of the quarter:

"We are too much under pressure. At the end of the quarter, the six weeks within the quarter, all the nice talk about leadership and coaching and all these things simply disappear and at 'IT company' you move back to fight and fire. Unless you achieve your numbers the financial markets will shout. So the priorities are shifted to the transactional model again." (Sales Leader/Europe)

These results are consistent with prior research that established a link between coaching and performance (MacKenzie, Podsakoff, and Rich 2001; Deeter-Schmelz, Goebel, and Kennedy 2008; Shannahan, Bush, and Shannahan 2013). While previous literature discussed and tested coaching and performance, it did not identify the specific form the behavior should take in the sales context. Insights derived from our interviews provide a more detailed and textured understanding of sales coaching, responding to the call to research from MacKenzie, Podsakoff, and Rich (2001).

Finally, this research provides confirmatory evidence that sales leaders who engage in coaching serve an important mentoring role to their salespeople (Mosca, Fazzari, and Buzza 2010), and that sales coaching only happens if it is made a clear and consistent priority by the sales leader (Good 1993). The respondents suggested that coaching worked best when individual coaching sessions were booked monthly with consistency. As well, it was suggested that it is important to ensure coaching occurs at all levels, including both senior and mid-level sales leaders.

In summary, coaching was the most cited behavior that could enable salesperson performance. Sub-themes of coaching included 1) coaching for individual development and 2) coaching of the sales process, including both the art and science (leading and lagging metrics) of sales. Trust was 
identified as a potential mediator by which coaching influence salesperson performance. To ensure coaching occurs, it is best to schedule coaching sessions on a regular basis.

\section{Collaborating Behavior}

"My leader does an extremely good job. I think she is the best in the company at what she does by the way. She is bringing everybody together, so you have got a lot more knowledge. If you think two brains work a lot better than one to solve a problem, imagine six and seven brains!" (Salesperson/Commonwealth)

Collaboration (or collaborating) was a main theme and represented the second most popular leader behavior identified by our sample. This behavior is defined as organizing, facilitating, and leading group activities in which the salespeople were encouraged to interact with and learn from each other as they solve problems as a team. When sales leaders engage in the collaborating behavior they enable their salespeople both give and receive help - not only from their fellow salespeople, but also from internal colleagues associated with other parts of the organization. This includes help solving customer problems. Brainstorming and generating new ideas are also important aspects to this leader behavior. There were also discussions about team building, which was discussed as an important result of collaboration, as illustrated in the quotation above.

Further analysis identified three behavioral sub-themes of collaboration: facilitating, encouraging, and role modeling collaborative behavior. Facilitating collaboration is when leaders organize meetings and conference calls so their salespeople can talk to each other. A sales leader described how this gives them an opportunity to:

"share and bring ideas to the table and help each other during this monthly two-hour session. It's a great way of doing it because we get maximum attention from everyone." (Sales Leader/Commonwealth) 
The talks might involve sharing wins and losses, identifying best sales practices, and/or providing both internal and external contacts to each other. This peer-to-peer interaction occurs because the leader has organized activities that lend themselves to collaboration.

"I ask the sales rep to make a prioritize list and then I let him present his tier one customers to a group of people [managers]...the most important reason why I am doing this is if you are sitting side by side with 6 people discussing the sales cycle, you always get the brilliant ideas." (Sales Leader/Europe)

This was the most referenced sub-theme by both sets of respondents, but in particular by the salespeople, who seem to especially appreciate sales leaders who facilitate collaboration.

The second sub-theme is encouraging collaboration, which is when leaders themselves speak out about the importance of working together as a team. This is a verbal activity where the leader argues for why it makes sense to collaborate with colleagues. Encouraging might also involve sharing ideas in impromptu brainstorming sessions to generate new ideas. Encouraging collaboration within the team was deemed to be important by both sales leaders and salespeople:

"I am always an advocate for [leaders encouraging] brain-sharing knowledge during collaboration. Because most people will know the answer and you just need to know who holds the information." (Salesperson/Europe)

"I hope I'm building sales excellence by [encouraging] learning from others, because what somebody does in one part may be relevant in a slightly different way or applied in a different way I should say to another part. We can all be successful when we learn from each other." (Sales Leader/Commonwealth)

Finally, leaders exhibiting collaborative behavior are role models, in that they provide a behavioral example of how to be a team player. This is distinct from the previously discussed role modeling dimension of coaching, which focuses on how to sell. For collaboration, sales leaders model how to actively share ideas with others in the organization, including non-sales personnel, and treating all of these co-workers with respect 
"I like that they use me to get their collaboration with the team. They work together, find solutions together. They don't need me every time, it's just constant learning." (Sales Leader/Commonwealth)

Our interview discussions about collaboration evoked certain aspects of transformational leadership. For example, House (1977) points to the importance of collective efficacy, indicating that groups are more effective when all members share the belief that they can reach their goals through unified efforts. Collaboration closely resembles fostering the acceptance of group goals, which has been shown to be effective in a sales context (MacKenzie, Podsakoff, and Rich 2001; Schwepker and Good 2010). These scholars of transformational leadership argue that effective leaders persuade their subordinates to forego personal goals in order to achieve a common higher-order team goal; in this research, it is knowledge pooling and shared problem-solving that are elicited. A different perspective on collaboration comes from the servant leadership literature, which posits that leaders should develop community that allows followers to identify with and value something greater than themselves. This behavior is effective in part because it creates a safe environment where followers feel connected to each other (Spears 2002); this research indicates that mutual learning might make that connection.

Bass (1997) found that collaboration with outsiders (e.g., business partners) is important to effective selling. Collaboration with customers to create solutions that meet the customer's needs was identified by the respondents in the present research as a key trend in the current sales environment. As this skill is important to the salesperson to enable sales performance, it is vital that the sales leader appreciate and use this behavior to assist in the sales process. 
Our research suggested that great sales performers work collaboratively and can orchestrate internal and external resources for the customer. One sales leader described this as working with an ecosystem of experts:

"We need to work first with partners outside of 'IT company' and internally you need to be able to orchestrate the various resources that you have at your disposal..... That is what 'IT company' is when we talk about sales, it is quite a complex ecosystem of experts...." (Sales Leader/Europe)

Respondents indicated that sales leaders can help with collaborative networking, both internally and externally. They stated that this type of performance enabling collaboration not only fosters teambuilding but also helps gain access to resources.

The importance of working collaboratively in sales has been identified as a needed direction for sales research (Ingram et al. 2005). More recently, it has been suggested that "salespeople must collaborate, not conquer" (Dixon and Tanner 2012, 12). The findings in this present study are consistent with previous research that discusses the importance of collaboration (Cespedes, Doyle, and Freedman 1989; Dixon and Tanner 2012; Evans et al. 2012; Ingram et al. 2005; Üstüner and Godes 2006). While the importance of collaboration was identified in the sales literature (Evans et al. 2012), this has not been called out as a separate leader behavior in the mainstream leadership literature. We contribute to this research stream by identifying collaboration as a leader behavior and by exploring multiple dimensions of collaborative behavior that is defined by sales professionals as being especially effective in a sales context.

In summary, collaboration is a sales leader behavior identified to enable salesperson performance. Leaders did this by 1) facilitating collaboration by providing conference calls and meetings in which their salespeople could share information and ideas 2) encouraging collaborative behavior verbally, and 3) role modeling collaborative behavior. 


\section{Championing Behavior}

"I think the higher up you go into sales management chain the more important it is for those sales managers to work across the organization to fix the problems that are getting in the way of you selling." (Sales Leader/Asia Pacific)

As demonstrated by this quote, effective sales leaders intervene on behalf of their salespeople in a way that protects them from tangential and/or nonessential work-tasks so that they can better focus on activities that are directly related to enhancing sales performance. Sales leaders can protect their salespeople by being a strong advocate for them throughout the organization. In addition, sales leaders can enable performance by solving internal problems for their salespeople. These sub-themes are described as intervening behaviors that keep indirect internal managers and repetitive internal processes from interfering with the salespersons' focus on generating revenue with customers. An example of using the championing behavior may be when the sales leader acts as an internal champion for the salesperson by blocking low value-add 'repetitive' inspection on sales opportunities, and helping with escalations internally. A salesperson defined the behavior as the following:

"Eliminating wherever possible non essential activity and non essential communications to the employee that are not directly in line with their task at hand (generating revenue)." (Salesperson/Europe)

We call this championing, which was our third most referenced leader behavior. We view this as a new finding in the sales management literature.

Salespeople's interaction with customers and business partners gives them access to a significant amount of marketplace knowledge that is essential to the planning function of the organization (Bass 1997). This can lead to colleagues from multiple divisions throughout the firm making information requests from the sales force. Responding to all these requests can distract the sales team from their core job -- selling. Salespeople discussed how they need shelter from these types 
of requests and appreciated leaders that engaged in protecting, clearing roadblocks, obtaining approvals, providing escalations, and reducing administration. Given the increased need for accountability in sales (Ingram et al. 2005), there was a clear view that sales performance could be enabled by sales leaders who champion causes and break down internal barriers for their salespeople. Thus, we see the championing leader behavior as necessary and important, particularly in the sales context.

In discussing championing, respondents provided a number of striking analogies about how leaders can act to shelter their team. For example, one salesperson said:

"Yeah, it's [like] ... in a battle or a war situation, you don't want a bomb dropping on you as you are trying to do your job, so that the analogy of people very high up without a contextual understanding are creating additional work which will not directly contribute to the closing or completion of the sale. So ... it's pretty much, the bomb is dropping, the noise that comes from people... who can't actually contribute directly to the closing or completion of the sales opportunity... It's air cover, keeping noise away from the frontline salespeople so that I can focus on executing sales deal as opposed to being dragged into more operational issues." (Salesperson/Commonwealth)

Sales leaders also discussed the importance of this leader behavior. One leader discussed how championing is needed now more than ever due to increasing complexity of the current sales environment:

"The point is as soon as we are under pressure we fall into these forecast reviews and a leader should be strong enough to create the space for thinking and reflection, and be strong enough to rise above the pressure, and protect his team from the pressure of the boat. He has to ... protect his team from the corporate noise and pressure, forecast pressure from regional president..." (Sales Leader/Europe)

When we asked another sales leader why it matters to 'protect' salespeople, the simple reply was:

"Because they should spend maximum time with the customer." (Sales Leader/Europe). 
The findings of this present research support Brashear et al.'s (1997) claim that more time spent focused on the client will lead to higher levels of performance. Another sales leader used a snow plough analogy to describe the championing leader behavior:

"As a manager, my task is to be the snowplow to run in front of you the sales rep, and clean out the clutter and help you have as much time as possible with the client ... it is about enabling focus." (Sales Leader/Europe)

Thus, the championing behavior is perceived to contribute to sales performance by allowing salespeople to focus on the client.

Another sub-theme of championing behavior that emerged involved a sales leader behavior of providing learning opportunities and new sales tools to their salespeople. Example quotations from a sales leader and a high-performing salesperson are as follows:

"My work as a leader is to ensure that all these guys are awesome and have awesome tools and processes to operate better with the customers. Because if they do that, I am successful." (Sales Leader/Asia Pacific)

"The training is imperative, getting good training and products training, so that at least you know what you are talking about. That is an enabler that can help." (Salesperson/Commonwealth)

Interestingly, the two sets of respondents tended to emphasize different aspects of championing. That is, salespeople generally discussed the protection aspects of championing, whereas sales leaders emphasized the importance of how this leader behavior enables the salespeople by providing internal escalations, new tools, and processes. For example, a sales leader may circulate an account report among the various internal teams that need the information in order to save the salesperson time. Leaders perceive this as performance enabling; salespeople see this behavior as one that protects their time. 
The championing leader behavior is perhaps the most striking leader behavior identified in this study. We can find no reference to anything like championing in past sales management literature, nor can we find this in the theories of transformational leadership or servant leadership. Adaptive leadership does involve a leader behavior called protecting voices from below. Specifically, this leader behavior is about ensuring that the viewpoints of all followers are heard, including both minority and majority voices (Heifetz 1994). To enable this protection, the leader needs to let go of some control and give the followers more control (Northouse 2016). By contrast, our finding relates to protection from pressures from above. Other research conducted outside of sales management has suggested that a new direction for leadership research may include examining the importance of "shielding" leadership processes (Jones and Kriflik 2006). This present study indicates that a championing leader behavior which both shields and enables salespeople is an important leader behavior to enable sales performance in large complex organizations such as the one used in this present research.

Finally, respondents spoke at length about how internal challenges and processes at their company interfered with their ability to focus on the customer and generate revenue, and they felt strongly that there was a clear link between championing and performance:

"My sales leader stood up and resisted the upper leadership and fought for me. The effect on me worked well. I regard him with a lot of respect, and it also makes me want to go that extra mile to perform and prove that my sales leader made the right decision when he had my back." (Salesperson/Middle East)

This research indicates that sales leaders should consider consciously using this behavior with their sales teams to help enable performance.

In summary, championing is a novel sales leader behavior identified to enable salesperson performance. Championing consists of sales leader behaviors that protect their salespeople from 
corporate 'noise' from above (questions from other divisions, unnecessary reporting etc.) and provide training and tools so that they can focus all attention on activities relevant to selling.

\section{Customer Engagement Behavior}

"We need our sales leadership, including myself to be out there, going to meetings at CIO and CEO's. Get out there and talk to board members of companies we don't do business with or we do... such that we can drive more sales." (Sales Leader/Commonwealth)

Many sales professionals stressed how the best sales leaders participate in customer engagement behavior that gives them a solid understanding of their salespeople's customers. We define customer engagement as a leader behavior that involves researching and/or interacting with customers to help progress sales deals, developing executive-customer relationships, and demonstrating to salespeople how to effectively provide value to customers. The following quotation provides insight into the importance of the sales leader engaging with customers:

"If the million-dollar deal is not moving, it's because somebody within the organization is not understanding the value of the proposition that we're putting across. So either we are not positioning right, or we are talking to the wrong people. And this is where the issues can be and sales leaders should help." (Salesperson/Asia Pacific)

In other words, it was felt that sales leaders should engage in customer-centric activities that give them a solid understanding of the customer's issues. Salespeople indicated that leaders were more effective at customer engagement when they could draw from a successful background as a salesperson:

"You need to show that you have been successful and you understand sales. You cannot come from outside." (Sales Leader/Europe)

Another interesting aspect to customer engagement is that it can involve the leader challenging the customer. For example, leaders can help win business by having tough conversations with customers about pricing or service practices. Respondents indicated that sales leaders, with their elevated status, are needed to help salespeople overcome certain challenges. 
As the quote at the beginning of this section illustrates, this status also gives them the ability to develop important relationships with customers that are C-level executives, which helps leverage salesperson performance.

Customer engagement is important because leaders are sometimes needed to work hand-in-hand with their salespeople throughout all phases of the sales process. This sometimes includes assistance in closing the sale. This sub-theme is demonstrated by the following quote:

"The leaders that I respond to best are those willing to be captains not coaches. Those who are willing to get out in the field, who want to move the ball, who want to take responsibility and want to proactively work with you on achieving the sale." (Salesperson/Commonwealth)

At the same time, leaders need to know when to get out of the way. That is, salespeople want their leaders to engage with customers, yet still prefer to take the lead in the selling process. This is consistent with research that found that salespeople do not value a sales leader who does the selling for them (Deeter-Schmelz, Goebel, and Kennedy 2008). As with coaching, at some point customer engagement becomes micromanaging, and could actually damage the salesperson's trust in the sales leader and credibility with customers. This was supported in our research; for example one sales leader stated:

"I think we [sales leaders] get in the way too much ... you think you are losing a deal, sometimes the temptation is you just step in because you are not going to have that deal lost...I think every time you do that, you betray trust and you dent the person's confidence." (Sales Leader/Commonwealth)

Finally, several respondents discussed how sales leaders may neglect customer engagement because they are too busy with other time-consuming managerial activities, such as reporting on the numbers.

"I find that many times, a sales manager's role is a lot about just feeding up numbers to go to the organization... but it should be that the sales manager should know at least at a 
conversational level what's happening in each of their accounts in which their salespeople are involved.” (Salesperson/Europe)

The effectiveness of customer engaging behavior makes sense in the context of servant leadership theory. That is, servant leaders put the needs of their followers first (Greenleaf 1970); so it follows that servant leaders also would take the time and effort to engage with their salespeople's customers - especially if those salespeople would like them to. In fact, salespeople in our sample were more likely than leaders to reference this behavior, suggesting that it is indeed the case that salespeople are looking for their leaders to engage with customers. This understanding of customers and customer engagement might occur alongside the coaching behavior of accompanying their salespeople in the field and actually meeting with customers.

In summary, customer engagement is a leader behavior identified to enable sales performance. Salespeople valued customer-centric leaders who work closely with them throughout the sales process to help them form and leverage close relationships with clients. Sales leaders understood that it is important to engage with customers in an appropriate manner, adding value to the process to help enable salesperson performance. Too much customer engagement by the leader, however, can be perceived as micromanagement.

\section{Mediating Variables}

As we explored and analyzed the data, four potential mediators that link sales leadership with sales performance emerged: trust, confidence, optimism, and resilience. The resulting conceptual model is shown in Figure 1. Identification of these variables is a key contribution of this research as it provides a better understanding of the process of how coaching, collaboration, championing, and customer engagement enable salesperson performance. 


\section{INSERT FIGURE 1 ABOUT HERE}

Trust, which was the most commonly referenced mediator by our respondents, plays a prominent role in the leadership literature, especially the theories of transformational leadership, servant leadership, and authentic leadership (Northouse 2016). In fact, a well-known leadership quote is that "trust is the lubrication that makes it possible for organizations to work" (Bennis and Nanus 1985, 43). A number of empirical studies have confirmed the importance of salesperson trust in manager as a mediator between the leader behaviors and performance (e.g., Podsakoff et al. 1990; MacKenzie, Podsakoff, and Rich 2001). Often, our sample discussed the importance of leader trust in subordinate salespeople (i.e., trust in the opposite direction). The viewpoint of one of our salespeople gives us further insight into the important role trust plays in the relationship between leadership and performance:

"On the other side, trust is a very good one. Trust your guys, you hired them, so you know they're a good salesperson, and they're trustworthy, and they are not in this role because they cannot do anything. Give a little bit of trust.....That's why everyone is willing to step up a little bit more, because they feel secure." (Salesperson/Europe)

In addition to trust, the present study identified confidence as a potential mediator of leader behavior and salesperson performance. Confidence is often equated to the academic construct of self-efficacy, which sales researchers have identified as one of the most important individual difference variables contributing to sales performance (e.g., Spiro and Weitz 1990; Yang, Kim, and McFarland 2011). When salespeople are confident, they have higher expectations of performance and are more motivated to take action. Transformational leaders have high expectations of their followers, which enhances the followers' confidence (House 1977; Northouse 2016). Authentic leadership theory posits that leaders should also have confidence, as it makes them more motivated to succeed, more persistent when obstacles arise, and more likely 
to welcome a challenge (Avolio and Gardner 2005; Northouse 2016). As reflected by the following quote, the current study supports the idea that confidence is important for both salespeople and sales leaders:

"Would it help if a sales leader was able to do behaviors that enabled confidence? 100\% yeah!! That's big. From sales there are a lot of rejections you can face from time to time, there's a lot of losses you may have throughout the course of your career. You may lose some big deals, you may lose deals and not understand why you lost them, because you think you did everything right in the book. I guess having a good sales leader with a lot of confidence and to give you that confidence saying no, you did a great job." (Salesperson/Commonwealth)

Optimism was the third most frequently referenced mediator in the current study. This is consistent with transformational leadership theory, which contends that effective leaders talk optimistically about the future in order to boost their followers' optimism and make them more engaged in their work (Tims, Bakker, and Xanthopoulou 2011). Empirical support for this has been found in the sales management literature (Rich 1999). Optimism is also central to authentic leadership, which stresses the importance of leaders being positive about both their capabilities and the outcomes they can achieve (Northouse 2016). In this regard, optimism works in conjunction with confidence. Both constructs are positive about the future. Our respondents argued that optimistic sales leaders can be instrumental in helping their salespeople to stay positive. Further, they stressed how optimism among salespeople is important in order to keep them motivated in the face of the continual challenges of a sales job:

"You want to be optimistic about things. You want to see chances and opportunities, see the opportunities and not see the down side of things.” (Salesperson/Europe)

Finally, resilience was identified as being an important mediating variable in the relationship between leadership and performance, though not referred to as frequently as the other three mediators, resilience was greatly emphasized by the respondents who discussed it in their responses. Resilience, which is often discussed in the popular press as being similar to 
perseverance and/or grit, is seen to be critical to success across a wide range of pursuits

(Duckworth 2016). Although this concept has not yet been examined extensively in the academic sales management literature, the following perspective suggests that it should be:

"You have to be able to carry that thing forward and you know, be wanting to come back the next day and start again and try again. So it takes a lot of resilience and I think a big part of it is, for a sales manager to be feeding that energy to people, so that they are convinced they are doing the right things." (Salesperson/Asia Pacific)

This finding chimes with authentic leadership theory which posits that resilience is one of four key positive psychological attributes that are important for leaders to possess - the other three are confidence, optimism, and hope (Luthans and Avolio 2003). Authentic leadership theory may provide a framework for understanding the respondents' comments regarding the importance of the mediators - especially confidence, optimism, and resilience. As discussed above, these three (of our four) mediators are central to that theory. Further, the theory holds that these variables are partly trait-like, but also have state-like qualities (Northouse 2016). The state-like quality means that they can be developed and improved, which is consistent with the perceptions of our respondents, who felt strongly about how sales leaders can have a positive influence on the confidence, optimism, and resilience of their salespeople.

In summary, four potential mediating variables were identified. The first, and most mentioned, was Trust. The other three - Confidence, Optimism, and Resilience - are individual psychological traits that can mediate how a salesperson will respond to key sales leader behaviors. This is an important finding as it allows us to connect these behaviors to specific leadership theories and to better understand the process through which sales leaders help their salespeople. 


\section{Similarities and Differences in Sales Leader and Salesperson Perceptions}

Taking a dual perspective to understand the sales leader and salesperson's perspectives was an important element of the research. Interestingly, the sales leaders and followers (i.e., salespeople) interviewed exhibited high agreement on four key leader behaviors that enable sales performance. Specifically, in terms of frequency of mention, the leader behaviors of coaching, collaborating, championing and customer engaging were present in the same order for both sales leaders and salespeople. These four leader behaviors represented 84 percent of total salesperson references and 79 percent of total sales leader references (Figure 2).

\section{INSERT FIGURE 2 ABOUT HERE}

Sales leaders spent substantially more of their interview time discussing coaching than did salespeople, perhaps because coaching forms a substantive part of the sales leader's role and is something they spend a lot of time doing. While coaching was the most frequently referenced sales leader behavior for salespeople, perhaps because they experience it as helpful and valuable, these respondents spent proportionately more of their interview time talking about collaborating, championing, and customer engaging than did sales leaders.

Finally, sales leaders made more references to leader behaviors in their interviews compared to salespeople. This suggests that sales leaders have more opinions about leadership than do their followers which probably reflects their greater familiarity with leadership roles.

\section{$4 \quad$ Summary and Managerial Implications}

The results of this global study provide insight into how sales leaders can manage salespeople through four key behaviors that are perceived to lead to improved sales performance. The ideas 
generated by this study should stimulate reflection about leadership practices in an environment driven by short term pressures and high requirements for performance for both sales leaders and salespeople. Specifically, this study provides a theoretical framework (Figure 1) that points to a model of sales leadership involving four key sales leader behaviors (coaching, collaborating, championing, and customer engaging). These behaviors are recognized by the international sales professionals in our study as producing superior sales results both because of their direct impact on salespeople and also because of their role in building trust, confidence, optimism, and resilience in the sales team.

The managerial implications of this are substantial, in that sales leaders could be trained or coached to use behaviors which could, in turn, impact the performance of their salespeople. First, sales organizations might develop leadership development programs that are structured around this framework and the development and utilization of these behaviors. Too often, sales organizations simply promote top salespeople to management and assume that they have the skills to lead the sales team. Indeed, development programs for sales leaders often do not even exist (Reid et al. 2017). Leadership training could start with a discussion of the behaviors among the leadership team. The learning process could include personal introspection, salesperson feedback, and other training techniques focused on generating greater sales performance through these behaviors. Organizations might also consider using techniques such as pulse surveys to monitor the levels of trust, confidence, optimism, and resilience experienced by their sales people.

Many sales leaders in our sample indicated they are overwhelmed with large role sets that include a number of administrative duties and responsibilities, such as recruiting and strategic 
planning. This makes it difficult to spend enough time directly engaging and interacting with their subordinate salespeople and their customers. Further, sales leaders indicate that they are under intense pressure to meet short term, quarterly targets; so they tend to neglect longer-term strategies that do not create immediate results. Coaching, collaborating, championing, and customer engaging tend to be longer-term strategies, and this research suggests that these leader behaviors are perceived to have a powerful impact on sales performance. Therefore, sales leaders should not only be trained in these leader behaviors, but they should also be given the time and incentives to apply them.

This study also identified trust, confidence, optimism, and resilience as key variables that might mediate the relationship between leadership and performance. When coupled with the four leader behaviors, these mediators point to the importance of sales leaders interacting with their subordinates in an ethical, supportive manner. Indeed, this implication is consistent with other sales research that strives to identify leader behaviors that are effective in directing sellers toward ethical behaviors, as well as sales performance (Schwepker and Good 2010).

\section{$5 \quad$ Limitations and Opportunities for Future Research}

This is the first empirical study using qualitative research of sales professionals to identify leader behaviors perceived to enable salesperson performance. Qualitative research gives rich, detailed information about the views of respondents, and is uniquely suited to unravelling complex phenomena; however, this exploratory approach is subject to several limitations. First, given that external validity is not a central goal of qualitative research, caution should be used in applying these results to other sales situations and companies. Further research across a wider context and larger sample would be needed before we could draw definitive conclusions about the precise 
impact of sales leader behaviors. Further, the sales professionals in our sample perceived a link between the identified leader behaviors and performance, but this study did not measure actual performance as this was considered confidential information to the participating company. This approach, however, does create an opportunity for future research to test and confirm the validity and generalizability of the results. A logical next step would be a quantitative analysis that assesses the relationships in our conceptual model. This approach would require creating new measurement scales for coaching, collaborating, championing, and customer engaging.

Moreover, this study was conducted in the distinctive context of a single complex, highly relational IT/software sales business. Although the respondents were sales professionals from around the world, all respondents worked at the same company. Furthermore, this company (and indeed this industry) is particularly high-pressure. Both sales leaders and salespeople commented on the pressure in their dynamic complex sales environment with its results focus and its accelerated rate of change. Despite working in a business-to-business and major sales environment, a context usually considered to be relationship-focused, the respondents in our study described the unrelenting pressure to achieve quarterly sales revenue targets. To some extent, this culture may have led to more frequent transactional leader behaviors and therefore to a heightened awareness of supportive behaviors (such as coaching) when they occurred. Future research could examine these leader behaviors across other sales environments, companies and industries given how work pressures, turnover rates, competition, and other factors can vary across contexts, and might examine how the new, pressure-driven sales environment is impacting aspects of management other than leadership (e.g., the sales team's moral judgement and ethical behavior). 
The global background of this study raises an interesting question of how sales leadership might vary across cultures. That is, the sample comes from 12 countries and four different regions of the world. However, our use of qualitative data with the given sample size does not allow us to address this. Again, this is a topic for future sales leadership researchers to pursue.

Another opportunity for future research is a more in-depth examination of the specific leader behaviors identified. Our study did not specifically examine whether the frequency of the key behaviors had an impact on sales performance. For example, some respondents believed that too much coaching was a form of micromanagement that could potentially hinder sales performance. There were similar concerns about too much customer engaging behavior. It may be that there is an optimal place in the middle where a modest amount of these behaviors are conducive to good performance. Future research might examine whether the degree to which a sales leader behavior is employed affects its efficacy and whether the relationship between the sales leader behavior and the outcome is linear or (as indicated in our study) there might be a diminishing or negative return to some leader behaviors.

In conclusion, this research uses a social constructionist approach to provide a new, integrative conceptual framework based on sales professionals' perceptions about how leadership impacts performance. From in-depth interviews with sales leaders and salespeople, the analysis identified coaching, collaborating, championing, and customer engaging as key leader behaviors perceived to enable salesperson performance. Further, the analysis identified trust, confidence, optimism, and resilience as potential mediating variables in the relationship between leadership and sales performance. The results contribute both to managerial practice and to the academic literature on sales leadership - and identify a number of opportunities for further research. 
Table 1 Leadership Theories referenced in JPSSM Sales Leadership Articles

\begin{tabular}{|c|c|}
\hline $\begin{array}{l}\text { Leadership Theory } \\
\text { - JPSSM Article }\end{array}$ & $\begin{array}{l}\text { Description of Corresponding } \\
\text { Leader Behaviors / Dimensions }\end{array}$ \\
\hline $\begin{array}{l}\text { Servant Leadership } \\
\text { - } \quad \text { Grisaffe, VanMeter, and Chonko (2016) } \\
\text { - Jaramillo, Bande, and Varela (2015) } \\
\text { - Schwepker and Schultz (2015) } \\
\text { - Jaramillo, Grisaffe, Chonko, and Roberts (2009a) } \\
\text { - Jaramillo, Grisaffe, Chonko, and Roberts (2009b) }\end{array}$ & $\begin{array}{l}\text { These } 5 \text { articles described servant leadership through the } \\
\text { leader behaviors from Liden et al. (2008): Emotional } \\
\text { healing, Creating value for the community, Conceptual } \\
\text { skills, Empowering, Helping subordinates grow and } \\
\text { succeed, Putting subordinates first, Behaving ethically }\end{array}$ \\
\hline $\begin{array}{l}\text { Transformational Leadership } \\
\text { - Mullins and Syam (2014) } \\
\text { - Schwepker and Good (2010) } \\
\text { - Shoemaker (1999) } \\
\text { - Rich (1998) } \\
\text { - Bass (1997) } \\
\text { - Russ, McNeilly, and Comer (1996) } \\
\text { - Comer, Jolson, Dubinsky, and Yammarino } \\
\text { (1995) } \\
\text { - } \text { Dubinsky, Yammarino, Jolson, and Spangler } \\
\text { (1995) }\end{array}$ & $\begin{array}{l}\text { These } 8 \text { articles most commonly presented } \\
\text { transformational leadership as conceptualized by Bass } \\
\text { (1985), with these dimensions: Idealized influence } \\
\text { (charisma), Inspirational motivation, Intellectual } \\
\text { stimulation, Individualized consideration, Contingent } \\
\text { reward, Management-by-exception, Laissez-faire. } \\
\text { Also referenced were the leader behaviors of Podsakoff } \\
\text { et al. (1990): Articulating a vision, Providing an } \\
\text { appropriate model, Fostering the acceptance of group } \\
\text { goals, High performance expectations, Individualized } \\
\text { support, and Intellectual stimulation }\end{array}$ \\
\hline $\begin{array}{l}\text { Leader-Member Exchange Theory } \\
\text { - Lagace (1990) }\end{array}$ & $\begin{array}{l}\text { This article defined leadership as a set of relationship- } \\
\text { based behaviors between the leader and follower } \\
\text { (Dansereau, Graen, and Haga 1975) }\end{array}$ \\
\hline $\begin{array}{l}\text { Path-Goal Theory } \\
\text { - Jaramillo and Mulki (2008) } \\
\text { - DeCarlo, Rody, and DeCarlo (1999) } \\
\text { - Jones, Kantak, Futrell, and Johnston (1996) }\end{array}$ & $\begin{array}{l}\text { These } 3 \text { articles focused on the supportive and } \\
\text { instrumental dimensions of leadership (Harris and } \\
\text { Ogbonna 2001; Hackman and Oldham 1974) }\end{array}$ \\
\hline $\begin{array}{l}\text { Ethical Leadership } \\
\text { - Schwepker (2015) }\end{array}$ & $\begin{array}{l}\text { This article drew from Brown, Trevino, and David (2005) } \\
\text { in defining ethical leader behaviors }\end{array}$ \\
\hline $\begin{array}{l}\text { Situational Approach } \\
\text { - Butler and Reese (1991) }\end{array}$ & $\begin{array}{l}\text { This article applied the situational approach (Hersey and } \\
\text { Blanchard 1977), contrasting high / low task behavior } \\
\text { with high / low relationship behavior }\end{array}$ \\
\hline $\begin{array}{l}\text { Behavioral Approach } \\
\text { - Mulki, Caemmerer, and Heggde (2015) }\end{array}$ & $\begin{array}{l}\text { This article focused on the leader behaviors of initiating } \\
\text { structure and consideration (House 1977) }\end{array}$ \\
\hline $\begin{array}{l}\text { Skills Approach } \\
\text { - Deeter-Schmelz, Goebel, and Kennedy (2008) }\end{array}$ & $\begin{array}{l}\text { This article examined the skills of communicating, } \\
\text { listening, human relations and being organized }\end{array}$ \\
\hline $\begin{array}{l}\text { Trait Approach } \\
\text { - Flaherty, Mowen, Brown, and Marshall (2009) }\end{array}$ & $\begin{array}{l}\text { This article focused on the importance of propensity to } \\
\text { lead, which was defined as a leadership trait }\end{array}$ \\
\hline
\end{tabular}


Table 2 - Sales Leader Behavior Constructs

\begin{tabular}{|c|c|c|}
\hline Sales Leader Behavior & Construct Definition & Sub-themes \\
\hline Coaching & $\begin{array}{l}\text { Providing individualized hands- } \\
\text { on assistance and instruction to } \\
\text { help salespeople recognize } \\
\text { opportunities to improve their job } \\
\text { performance. }\end{array}$ & $\begin{array}{l}\text { - Individualized Coaching } \\
\text { - Coaching the Sales Process }\end{array}$ \\
\hline Collaborating & $\begin{array}{l}\text { Organizing, facilitating, and } \\
\text { leading group activities in which } \\
\text { salespeople are encouraged to } \\
\text { interact with and learn from each } \\
\text { other as they solve problems as a } \\
\text { team to realize both shared and } \\
\text { individual sales goals. }\end{array}$ & $\begin{array}{l}\text { - Facilitating } \\
\text { - Encouraging } \\
\text { - Role Modeling }\end{array}$ \\
\hline Championing & $\begin{array}{l}\text { Intervening on behalf of } \\
\text { salespeople in a way that protects } \\
\text { them from tangential and/or non } \\
\text { essential work-tasks so that they } \\
\text { can better focus on activities that } \\
\text { are directly related to enhancing } \\
\text { sales performance. }\end{array}$ & $\begin{array}{l}\text { - Protecting } \\
\text { - Internal Championing } \\
\text { - Enabling/Learning }\end{array}$ \\
\hline Customer Engaging & $\begin{array}{l}\text { Researching and/or interacting } \\
\text { with customers to help progress } \\
\text { sales deals, develop executive- } \\
\text { customer relationships, and } \\
\text { demonstrate to salespeople how } \\
\text { to effectively provide value to } \\
\text { customers. }\end{array}$ & $\begin{array}{l}\text { - } \text { Customer Centricity } \\
\text { - Working Closely With } \\
\text { Salespeople } \\
\text { - Building Customer } \\
\text { Relationships }\end{array}$ \\
\hline
\end{tabular}




\section{Figure 1 Conceptual Framework}

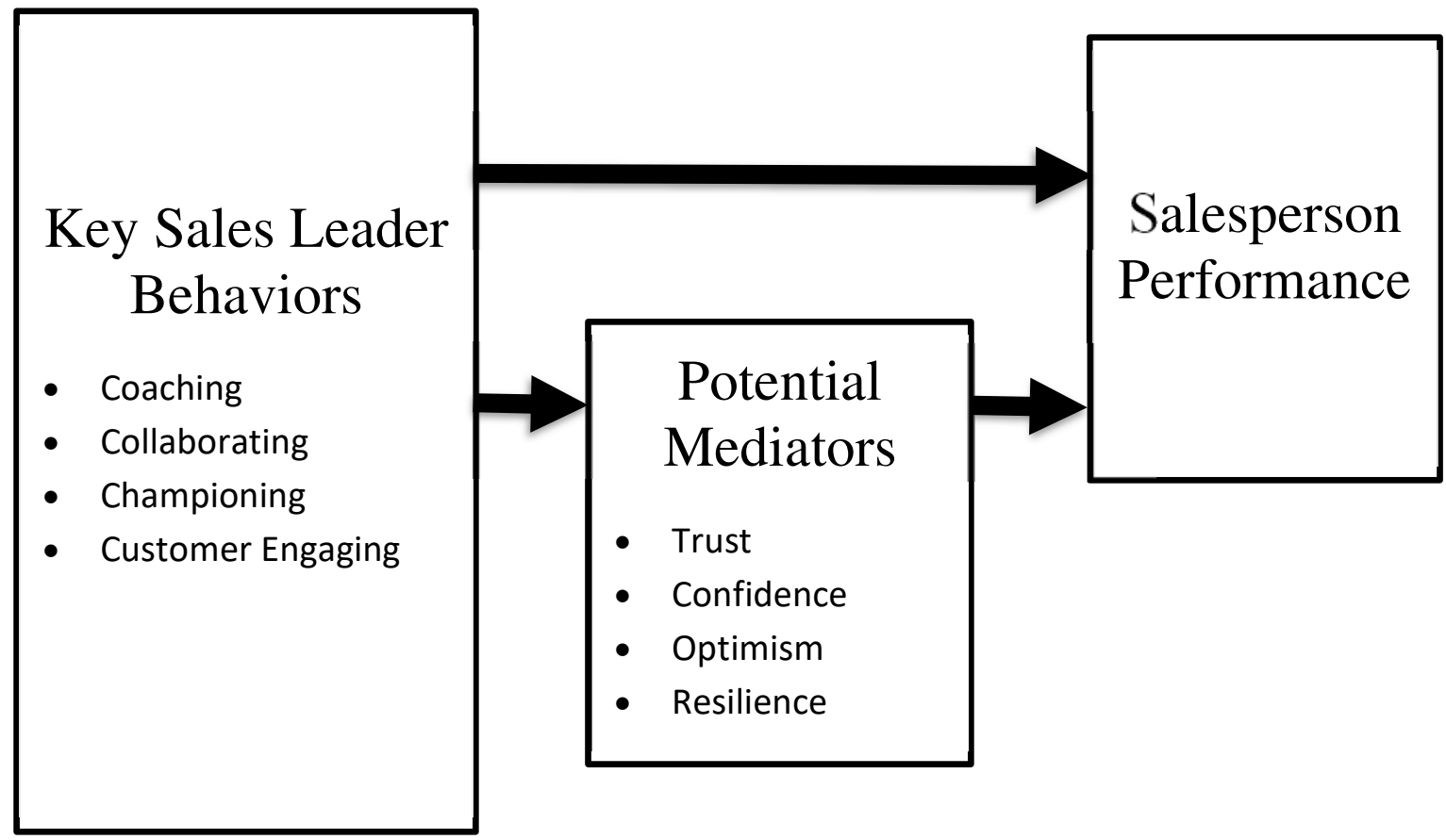


Figure 2 Percent Breakdown of References to Leader Behaviors by Salespeople and Sales Leaders

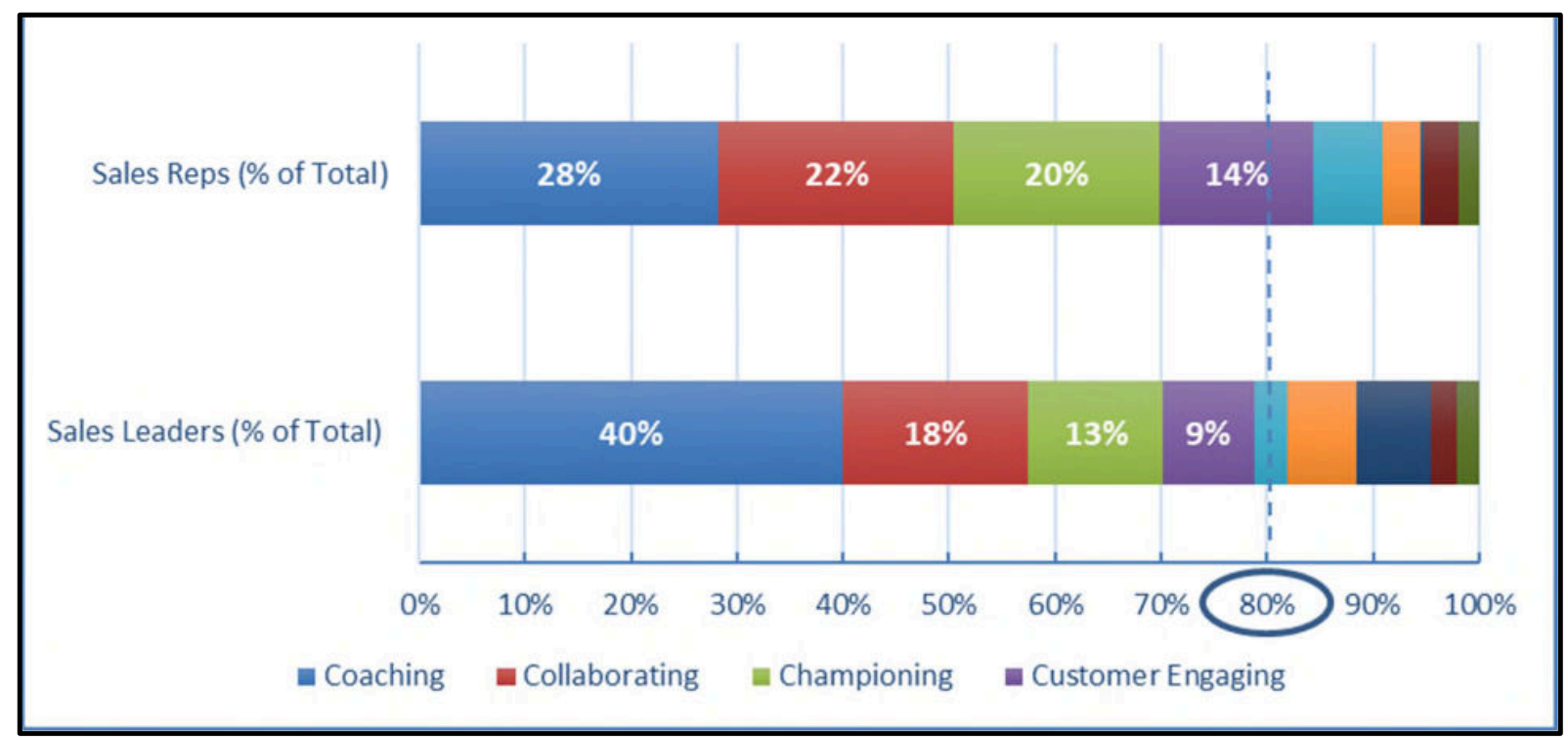




\section{References}

Albro, Scott. 2018. "Sales Enablement: The Who, What, How, When, and Why of Sales Enablement." TopoBlog. http://blog.topohq.com/sales-enablement-who-what-how-when-why/. Accessed June 16, 2018.

Avolio, Bruce J., and William L. Gardner. 2005. "Authentic Leadership Development: Getting to the Root of Positive Forms of Leadership." Leadership Quarterly 16 (3): 315-38.

Bass, Bernard M. 1985. Leadership and Performance Beyond Expectations. London; New York; Free Press.

Bass, Bernard M. 1997. "Personal Selling and Transactional/Transformational Leadership." Journal of Personal Selling and Sales Management 17 (3): 19-28.

Bazeley, Patricia, and Lyn Richards. 2000. The NVivo Qualitative Project Book. London: Sage.

Blaikie, Norman. 2007. Approaches to Social Enquiry. 2nd ed. Cambridge: Polity Press.

Bennis, Warren G., and Burt Nanus. 1985. Leaders: The Strategies for Taking Charge. New York: Harper \& Row.

Boehnke, Karen, Nick Bontis, Joseph J. DiStefano, and Andrea C. DiStefano. 2003.

"Transformational Leadership: An Examination of Cross-Cultural Differences and Similarities." Leadership and Organization Development Journal 24 (1): 5-15.

Brashear, Thomas G., Danny N. Bellenger, Hiram C. Barksdale, and Thomas N. Ingram. 1997. "Salesperson Behavior: Antecedents and Links to Performance." Journal of Business and Industrial Marketing 12 (3-4): 177-184.

Brown, Michael E., Linda K. Trevino, and Harrison A. David. 2005. "Ethical Leadership: A Social Learning Perspective for Construct Development and Testing." Organizational Behavior and Human Decision Processes 97: 117-134.

Butler, John K., and Richard M. Reese. 1991. "Leadership Style and Sales Performance: A Test of the Situational Leadership ${ }^{\circledR}$ Model." Journal of Personal Selling and Sales Management 11 (3): 37-46.

Cespedes F.V., Doyle, S.Z. and Freedman, R.J. 1989. "Teamwork for Today's Selling." Harvard Business Review 67 (4): 44-59.

Charmaz, Kathy. 2006. Constructing Grounded Theory: A Practical Guide through Qualitative Research. London: Sage Publications Ltd.

Comer, Lucette B., Marvin A. Jolson, Alan J. Dubinsky, and Francis J. Yammarino. 1995. "When the Sales Manager is a Woman: An Exploration into the Relationship Between Salespeople's Gender and Their Responses to Leadership Styles." Journal of Personal Selling and Sales Management 15 (4): 17-32. 
Dansereau Jr., Fred, George Graen, and William J. Haga. 1975. "A Vertical Dyad Linkage Approach to Leadership Within Formal Organizations. A Longitudinal Investigation of the Role Making Process." Organizational Behavior \& Human Performance 13 (1): 46-78.

DeCarlo, Thomas E., Raymond C. Rody, and James E. DeCarlo. 1999. "A Cross National Example of Supervisory Management Practices in the Sales Force." Journal of Personal Selling and Sales Management 19 (1): 1-14.

Deeter-Schmelz, Dawn R., Daniel J. Goebel, and Karen Norman Kennedy. 2008. "What Are the Characteristics of an Effective Sales Manager? An Exploratory Study Comparing Salesperson and Sales Manager Perspectives." Journal of Personal Selling and Sales Management 28 (1): 720 .

Dickie, Jim. 2017. "Salespeople Face an Uphill Battle, and AI Is Ready to Help: Sales Enablement Divisions Are Gaining Valuable Technology Partners." CRM Magazine 21 (9): 6.

Dixon, Andrea, and John F. Tanner. 2012. "Transforming Selling: Why It is Time to Think Differently About Sales Research." Journal of Personal Selling and Sales Management 32 (1): 9-13.

Dubinsky, Alan J., Francis J. Yammarino, Marvin A. Jolson, and William D. Spangler. 1995. "Transformational Leadership: An Initial Investigation in Sales Management." Journal of Personal Selling and Sales Management 15 (2): 17-31.

Duckworth, Angela. 2016. Grit: The Power of Passion and Perseverance. First Scribner hardcover ed. New York, NY: Scribner.

Easterby-Smith, Mark, Richard Thorpe, and Paul R. Jackson. 2008. Management Research. 3rd ed. London: Sage.

Evans, Kenneth R., Richard G. McFarland, Bart Dietz, and Fernando Jaramillo. 2012.

"Advancing Sales Performance Research: A Focus on Five Underresearched Topic

Areas." Journal of Personal Selling and Sales Management 32 (1): 89-106.

Flaherty, Karen E., John C. Mowen, Tom J. Brown, and Greg W. Marshall. 2009. "Leadership Propensity and Sales Performance Among Sales Personnel and Managers in a Specialty Retail Store Setting." Journal of Personal Selling and Sales Management 29 (1): 43-59.

Fontana, Andrea, and James H. Frey. 1994. "Interviewing: The Art of Science," in Handbook of Qualitative Research, edited by Norman K. Denzin and Yvonna S. Lincoln, 361-376. Thousand Oaks, CA: Sage.

Good, David J. 1993. "Coaching Practices in the Environment." Journal of Business and Industrial Marketing 8(2): 53-60.

Greenleaf, Robert K. 1970. The Servant as Leader. Cambridge, MA: Center for Applied Studies. Greenleaf, Robert K. 1972. The Institution as Servant. Westfield, IN: Greenleaf Center for Servant Leadership.

Greenleaf, Robert K. 1977. Servant Leadership: A Journey into the Nature of Legitimate Power and Greatness. New York: Paulist Press. 
Grisaffe, Douglas B., Rebecca VanMeter, and Lawrence B. Chonko. 2016. "Serving First For the Benefit of Others: Preliminary Evidence for a Hierarchical Conceptualization of Servant Leadership." Journal of Personal Selling and Sales Management 36 (1): 40-58.

Guarte, Jacqueline M., and Erniel B. Barrios. 2006. "Estimation under Purposive Sampling." Communications in Statistics -- Simulation and Computation 35 (2): 277-84.

Hackman, J. Richard, and Greg R. Oldham. 1974. The Job Diagnostic Survey: An Instrument for the Diagnosis of Jobs and the Evaluation of Job Redesign Projects. Department of Administrative Sciences: Yale University.

Harris, Lloyd C., and Emmanuel Ogbonna. 2001. "Leadership Style and Market Orientation: An Empirical Study." European Journal of Marketing 35 (5/6): 744-764.

Hersey, Paul, and Ken Blanchard. 1977. Management of Organizational Behavior: Utilizing Human Resources 3rd ed. Englewood Cliffs, NJ: Prentice Hall.

Heifetz, Ronald A. 1994. Leadership Without Easy Answers. Cambridge, MA: Belknap Press.

House, Robert J. 1977. "A 1976 Theory of Charismatic Leadership.” In Leadership: The Cutting Edge, edited by James G. Hunt and Lars L. Larson, 189-207. Carbondale, USA: Southern Illinois University Press.

Howell, Jane M. and Bruce J. Avolio. 1993. “Transformational Leadership, Transactional Leadership, Locus of Control, and Support for Innovation." Journal of Applied Psychology 78 (6): 891-902.

Ingram, Thomas N., Raymond W. LaForge, and Thomas Leigh. 2002. "Selling in the New Millennium: A Joint Agenda," Industrial Marketing Management 31 (7): 559-567.

Ingram, Thomas N., Raymond W. LaForge, William B. Locander, Scott B. MacKenzie, and Philip M. Podsakoff. 2005. "New Directions in Sales Leadership Research." Journal of Personal Selling and Sales Management 25 (2): 137-54.

Jaramillo, Fernando, and Jay Prakash Mulki. 2008. "Sales Effort: The Intertwined Roles of the Leader, Customers, and the Salesperson." Journal of Personal Selling and Sales Management 28 (1): 37-51.

Jaramillo, Fernando, Belén Bande, and Jose Varela. 2015. "Servant Leadership and Ethics: A Dyadic Examination of Supervisor Behaviors and Salesperson Perceptions." Journal of Personal Selling and Sales Management 35 (2): 108-24.

Jaramillo, Fernando, Douglas B. Grisaffe, Lawrence B. Chonko, and James A. Roberts. 2009. "Examining the Impact of Servant Leadership on Sales Force Performance." Journal of Personal Selling and Sales Management 29 (3): 257-76.

Jaramillo, Fernando, Douglas B. Grisaffe, Lawrence B. Chonko, and James A. Roberts. 2009. "Examining the Impact of Servant Leadership on Salesperson's Turnover Intention." Journal of Personal Selling and Sales Management 29 (4): 351-65. 
Jones, Eli, Steven P. Brown, Andris A. Zoltners, and Barton A. Weitz. 2005. "The Changing Environment of Selling and Sales Management." Journal of Personal Selling and Sales Management 25 (2): 105-11.

Jones, Eli, Donna Massey Kantak, Charles M. Futrell, and Mark W. Johnston. 1996. "Leader Behavior, Work-Attitudes, and Turnover of Salespeople: An Integrative Study." Journal of Personal Selling and Sales Management 16 (2): 13-23.

Jones, Robert, and George Kriflik. 2006. "Subordinate Expectations of Leadership Within a Cleaned-up Bureaucracy: A Grounded Theory Study." Journal of Organizational Change Management 19 (2): 154-172.

Ladkin, Donna. 2010. Rethinking Leadership: A New Look at Old Leadership Questions. Cheltenham: Edward Elgar.

Lagace, Rosemary R. 1990. "Leader-Member Exchange: Antecedents and Consequences of the Cadre and Hired Hand." Journal of Personal Selling and Sales Management 10 (1): 11-9.

Liden, Robert C., Sandy J. Wayne, Hao Zhao, and David Henderson. 2008. "Servant Leadership: Development of A Multidimensional Measure and Multi-Level Assessment." Leadership Quarterly 19, 161-177.

Liden, Robert C., Alexandra Panaccio, Jia Hu, Jeremy Meuser. 2014. "Servant Leadership: Antecedents, Consequences, and Contextual Moderators." In The Oxford Handbook of Leadership and Organizations, edited by David V. Day. Oxford: Oxford University Press. Lincoln, Yvonna S., and Egon G. Guba. 1985. Naturalistic Inquiry. Beverly Hills, CA: Sage. Lincoln, Yvonna S., and Egon G. Guba. 2000. "Paradigmatic Controversies, Contractions and Emerging Confluences." In Handbook of Qualitative Research, 2nd ed., edited by Norman K. Denzin and Yvonna S. Lincoln, 163-188. Thousand Oaks, CA: Sage.

Lofland, John., David Snow, Leon Anderson, Lyn Loftland. 2006. Analyzing Social Settings: A Guide to Qualitative Observation and Analysis. Belmont, CA: Wadsworth/Thomson Learning.

Luthans, Fred, and Bruce J. Avolio. 2003. “Authentic Leadership Development.” In Positive Organizational Scholarship, edited by Kim S. Cameron, Jane E. Dutton, and Robert E. Quinn, 241-258. San Francisco: Berrett-Koehler.

MacKenzie, Scott B., Philip M. Podsakoff, and Gregory A. Rich. 2001. "Transformational and Transactional Leadership and Salesperson Performance." Journal of the Academy of Marketing Science 29 (2): 115-34.

Maykut, Pamela, and Richard Morehouse. 1994. Beginning Qualitative Research: A Philosophic and Practical Guide. London: Falmer Press.

Miles, Matthew B., and A. Michael Huberman. 1994. Qualitative Data Analysis. 2nd ed. Thousand Oaks, CA: Sage.

Mosca, Joseph B., Alan Fazzari, and John Buzza. 2010. "Coaching to Win: A Systematic Approach to Achieving Productivity Through Coaching." Journal of Business and Economics Research 8 (5): 115-130. 
Mulki, Jay P., Barbara Caemmerer, and Githa S. Heggde. 2015. "Leadership Style, Salesperson's Work Effort and Job Performance: The Influence of Power Distance." Journal of Personal Selling and Sales Management 35 (1): 3-22.

Mullins, Ryan, and Niladri Syam. 2014. "Manager-Salesperson Congruence in Customer Orientation and Job Outcomes: The Bright and Dark Sides of Leadership in Aligning Values." Journal of Personal Selling and Sales Management 34 (3): 188-205.

Northouse, Peter G. 2016. Leadership Theory and Practice. 6th ed. Thousand Oaks, CA: Sage.

Podsakoff, Philip M., Scott B. MacKenzie, Robert H. Moorman, and Richard Fetter. 1990.

"Transformational Leader Behaviors and their Effects on Followers' Trust in Leader, Satisfaction, and Organizational Citizenship Behaviors." Leadership Quarterly 4 (1): 1-44.

Reid, David A., Richard E. Plank, Robert M. Peterson, Gregory A. Rich (2017), "Examining the Use of Sales Force Management Practices." Journal of Business and Industrial Marketing, 32 (7): 974-986.

Rich, Gregory A. 1998. "The Constructs of Sales Coaching: Supervisory Feedback, Role Modeling and Trust.” Journal of Personal Selling and Sales Management 18 (1): 53-63.

Rich, Gregory A. 1999. "Salesperson Optimism: Can Sales Managers Enhance It and So What If They Do?" Journal of Marketing Theory and Practice 7 (1): 53-63.

Ritchie, Jane, Jane Lewis, Carol McNaughton-Nicholls, and Rachel Ormston. 2014. Qualitative Research Practice. 2nd ed. London: Sage.

Russ, Frederick A., Kevin M. McNeilly, and James M. Comer. 1996. "Leadership, Decision Making and Performance of Sales Managers: A Multi-Level Approach.” Journal of Personal Selling and Sales Management 16 (3): 1-15.

Schwepker, Charles H. 2015. "Influencing the Salesforce Through Perceived Ethical Leadership: The Role of Salesforce Socialization and Person-Organization Fit on Salesperson Ethics and Performance.” Journal of Personal Selling and Sales Management 35 (4): 292-313.

Schwepker, Charles H., and Roberta J. Schultz. 2015. "Influence of the Ethical Servant Leader and Ethical Climate on Customer Value Enhancing Sales Performance." Journal of Personal Selling and Sales Management 35 (2): 93-107.

Schwepker, Charles H., and David J. Good. 2010. "Transformational Leadership and Its Impact on Sales Force Moral Judgment.” Journal of Personal Selling and Sales Management 30 (4): 299-317.

Shannahan, Kirby L., Alan J. Bush, and Rachelle J. Shannahan. 2013. “Are Your Salespeople Coachable? How Salesperson Coachability, Trait Competitiveness, and Transformational Leadership Enhance Sales Performance." Journal of the Academy of Marketing Science 41 (1): 40-54.

Shoemaker, Mary E. 1999. "Leadership Practices in Sales Managers Associated with the SelfEfficacy, Role Clarity, and Job Satisfaction of Individual Industrial Salespeople." Journal of Personal Selling and Sales Management 19 (4): 1-19. 
Spears, Larry C. 2002. "Tracing the Past, Present, and Future of Servant-Leadership." In Focus

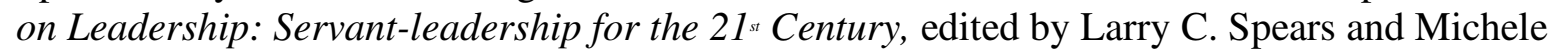
Lawrence, 1-16. New York: Wiley.

Spiro, Rosann L., and Barton A. Weitz. 1990. "Adaptive Selling: Conceptualization, Measurement, and Nomological Validity." Journal of Marketing Research 27 (1): 61-69.

Strauss, Anselm, and Juliet Corbin. 1998. Basics of Qualitative Research: Grounded Theory Procedures and Techniques. 2nd ed. London: Sage.

Tims, Maria, Arnold B. Bakker, and Despoina Xanthopoulou. 2011. "Do Transformational Leaders Enhance Their Followers' Daily Work Engagement?” Leadership Quarterly 22, 121131.

Üstüner, Tuba and David B. Godes. 2006. "Better Sales Networks." Harvard Business Review 84 (7/8): 102-112.

Yang, Byunghwa, Youngchan Kim, and Richard G. McFarland. 2011. "Individual Differences and Sales Performance: A Distal-Proximal Mediation Model of Self-Efficacy, Conscientiousness, and Extraversion." Journal of Personal Selling and Sales Management 31 (4): 371-382. 


\section{Web Index A: Interview Protocols}

Final interview protocol, Sales Leader

Research Question: What sales leadership behaviors are perceived to enable salesperson performance?

Core questions in yellow

Welcome, explain the interview purpose: to explore sales professional's perceptions of leadership behaviors that enable sales performance, explain the confidentiality of the process, and obtain informed consent.

1) Demographic information: Age, role, highest level of education, time in sales/sales leader. What percentage of your time do you spend actually selling? etc.

2) Please describe what constitutes exceptional salesperson performance in your business, is there anything else?

3) Are there any other aspects that are formally considered part of salesperson performance at your company?

4) Could you please describe in your own words, what constitutes high salesperson performance for you specifically? (Please consider outcome and behavioral sales performance).

5) Based on your experience, how does a sales leader enable salesperson's performance?

6) In your view, how do you as a sales leader facilitate/enable salesperson's performance? Tell me more

7) How might you as a sales leader hinder salesperson's performance? Tell me more

8) Think of your immediate sales leader or another sales leader. What could she or he do to help you improve your performance in sales? For example, what would you like your own manager to do more of? Less of? Why?

9) What specific actions/behaviors can a sales leader do to enable sales performance?

10) Is there anything else that we may have missed in terms of sales leadership behaviors and the way in which to account for achieving high sales performance?

11) Can you please summarise the top 5 leadership behaviors that you perceive to enable salesperson performance?

Probes will be used for elaboration and to clarify during analysis. Also the researcher will demonstrate effective listening skills. Examples of probes for elaboration:

"Could you elaborate on this...?" "Could you be more specific..?" "Was this expected...?"

"Could you tell me more about ...?" "Can you give me an example?"

"What do you mean by that?" 
Final interview protocol, Salesperson

Research Question: What sales leadership behaviors are perceived to enable salesperson performance?

\section{Core questions in yellow}

Welcome, explain the interview purpose: to explore sales professional's perceptions of leadership behaviors that enable sales performance, explain the confidentiality of the process, and obtain informed consent.

1) Demographic information: Age, role, highest level of education, time in sales/sales leader. What percentage of your time do you spend actually selling? etc.

2) Please describe what constitutes exceptional salesperson performance in your business, is there anything else?

3) Are there any other aspects that are formally considered part of salesperson performance at your company?

4) Could you please describe in your own words, what constitutes high salesperson performance for you specifically? (Please consider outcome and behavioral sales performance).

5) Based on your experience, how does a sales leader enable salesperson's performance?

6) In your view, how does your sales leader facilitate/enable salesperson's performance? Tell me more

7) How might your sales leader hinder salesperson's performance? Tell me more

8) Think of your immediate sales leader or another sales leader. What could she or he do to help you improve your performance in sales? For example what would you like your own manager to do more of? Less of? Why?

9) What specific actions/behaviors can a sales leader do to enable sales performance?

10) Is there anything else that we may have missed in terms of sales leadership behaviors and the way in which to account for achieving high sales performance?

11) Can you please summarise the top 5 leadership behaviors that you perceive to enable salesperson performance?

Probes will be used for elaboration and to clarify during analysis. Also the researcher will demonstrate effective listening skills. Examples of probes for elaboration:

"Could you elaborate on this...?" "Could you be more specific..?" "Was this expected...?"

"Could you tell me more about ...?" "Can you give me an example?"

"What do you mean by that?" 


\section{Web Index B: Coding Map \\ Theme 1}

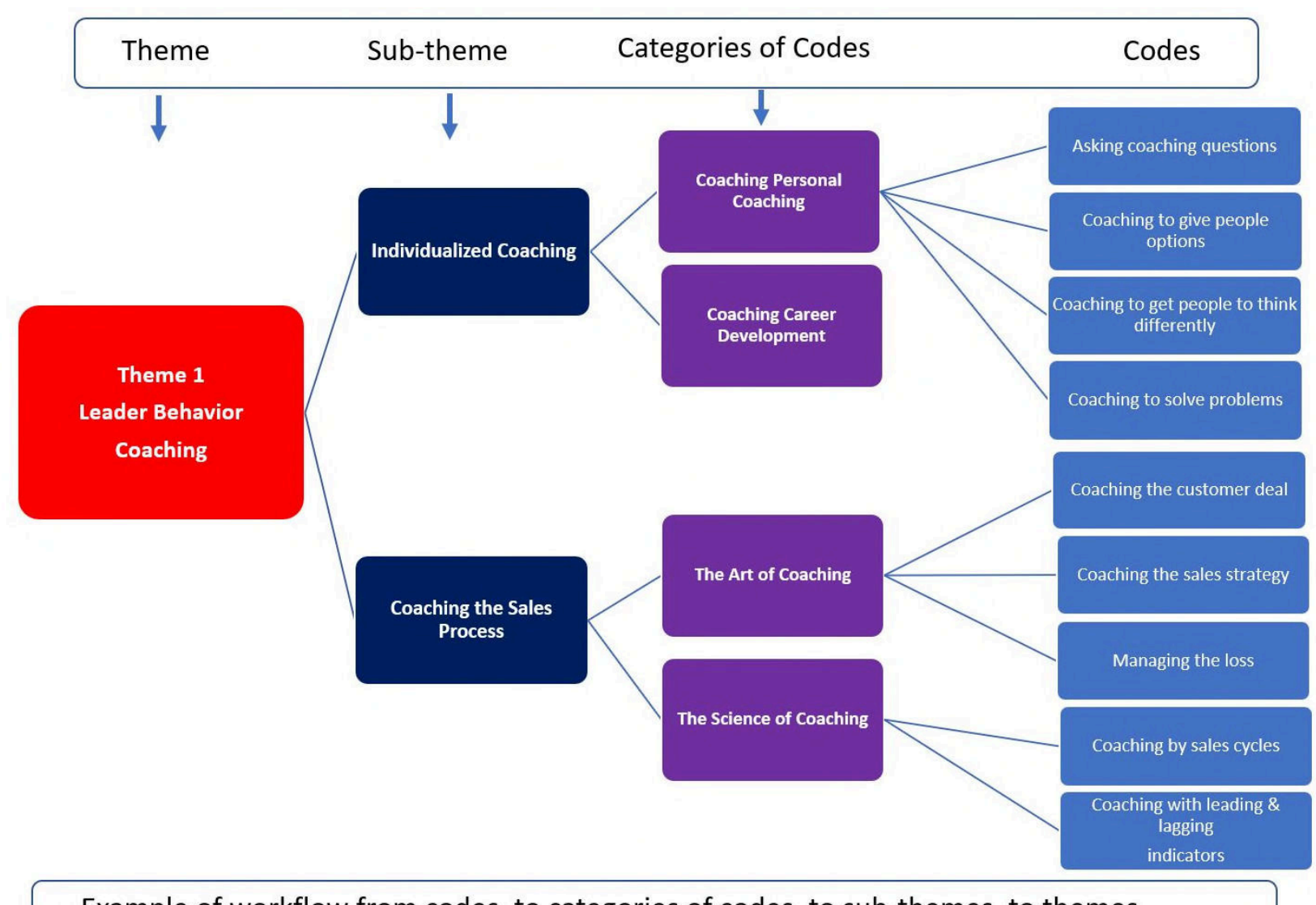

Example of workflow from codes, to categories of codes, to sub-themes, to themes 


\section{Web Index B: Coding Map \\ Theme 2}

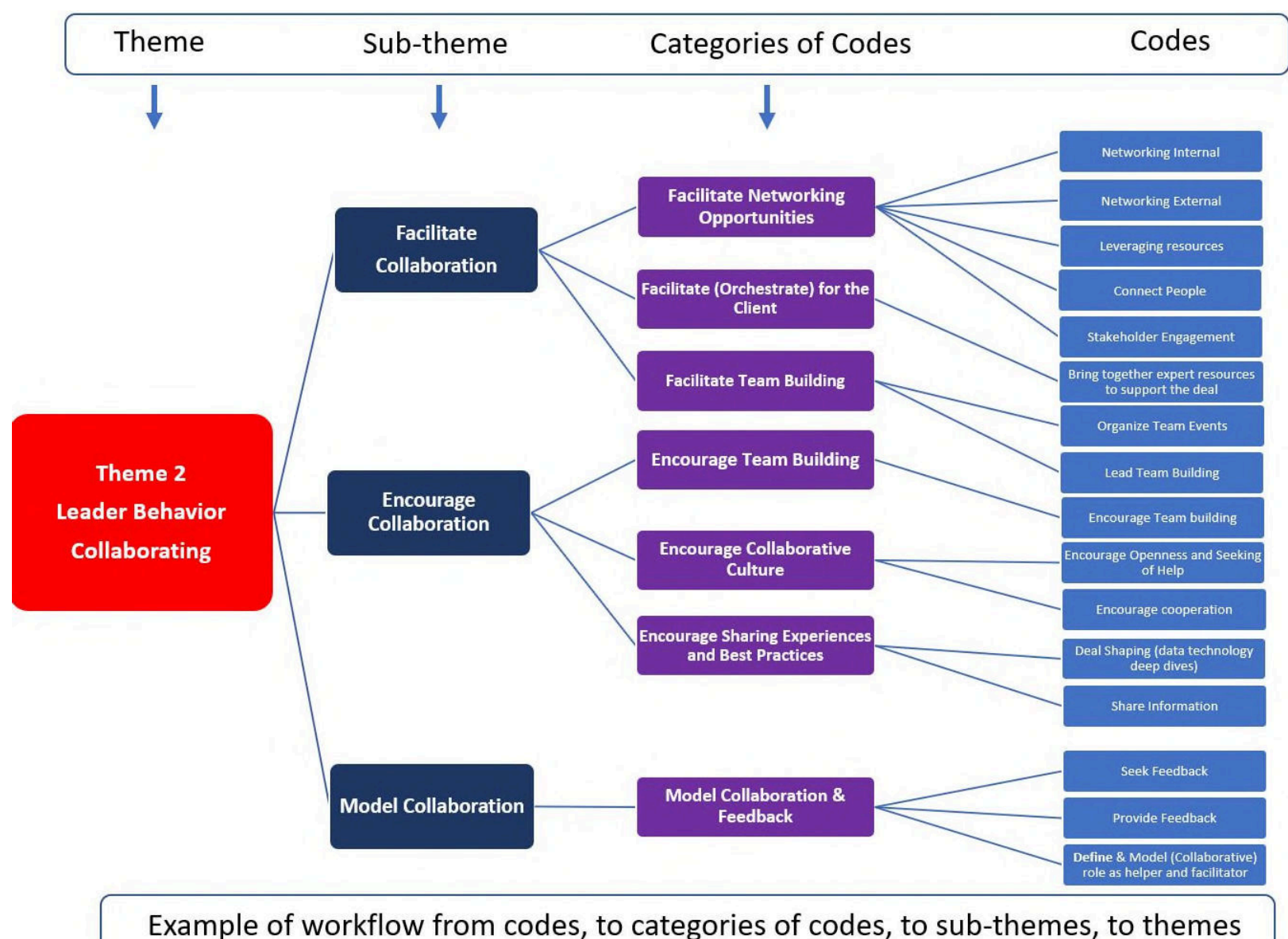




\section{Web Index B: Coding Map \\ Theme 3}

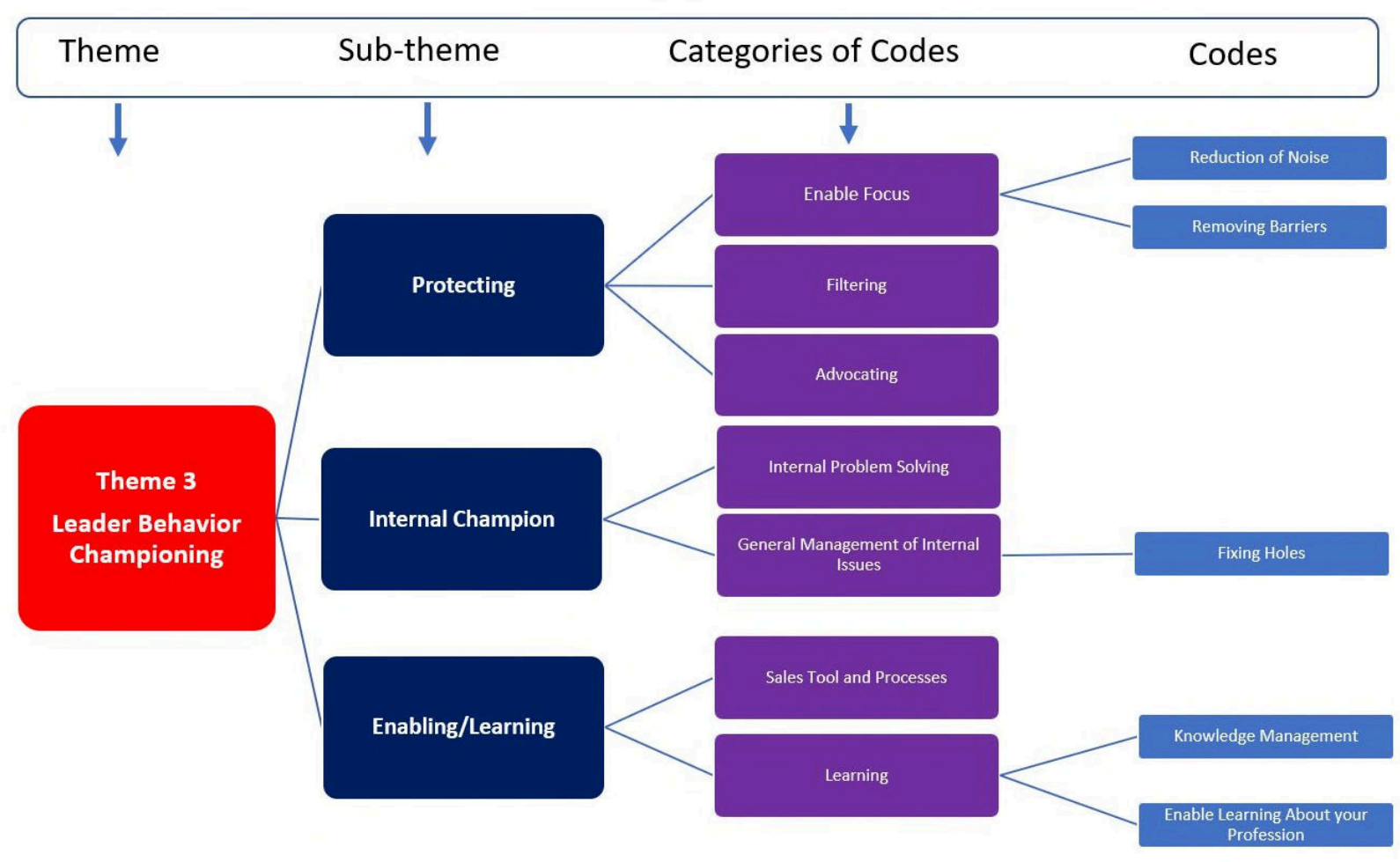

Example of workflow from codes, to categories of codes, to sub-themes, to themes 


\section{Web Index B: Coding Map \\ Theme 4}

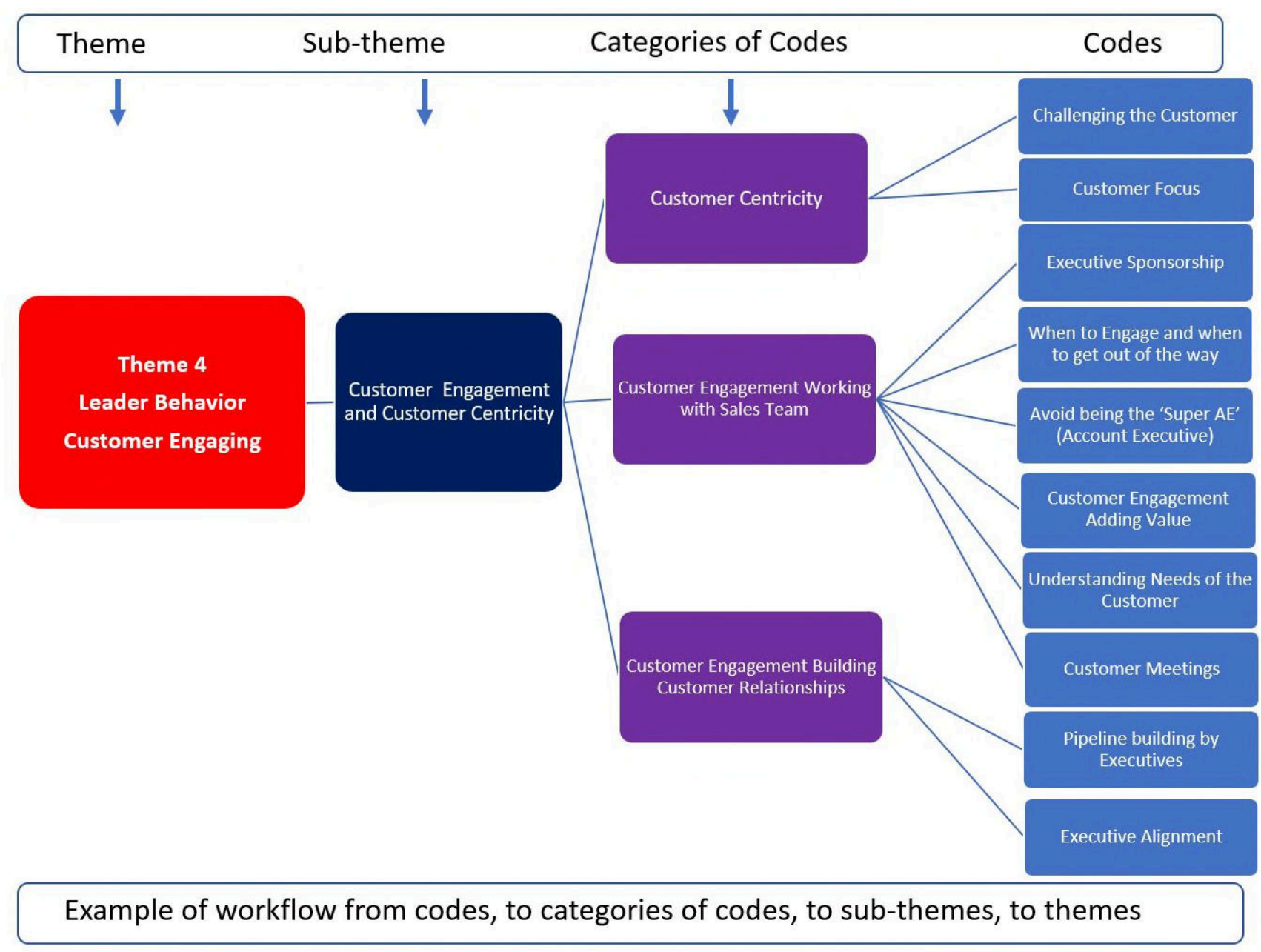

